\title{
Comunidad indígena, imaginario monárquico, agravio y economía moral durante el segundo imperio mexicano
}

\author{
Aimer Granados García
}

EL COLEGIo de MÉxico

Este artículo descubre algunos aspectos del imaginario político de comunidades indígenas durante el segundo imperio. La supervivencia de un imaginario monárquico y sus ideales de justicia y buen gobierno. Igualmente explora el agravio y la economía moral suscitados en ellas a raíz de los cambios introducidos por la independencia y la reforma.

\section{INTRODUCCIÓN}

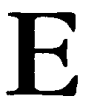
dmundo O'Gorman estableció que al menos hasta 1867 , en términos políticos, el ser nacional de México osciló entre el republicanismo y el monarquismo. Para O'Gorman es un hecho que la monarquía, como poderoso rival del sistema republicano y especialmente del federalismo, tuvo en un tiempo un vigor innegable entre los mexicanos. ${ }^{1}$ No obstante, en relación con la intervención francesa y el segundo imperio,

\footnotetext{
${ }^{1}$ O'Gorman, Supervivencia, 1969, p. 5.
}

una interpretación tradicional de la historia nacional ha ocultado la posibilidad del ser nacional monárquico que tuvo México durante esa etapa de su historia. $^{2}$

En su ensayo sobre la supervivencia política novohispana y las reflexiones sobre el monarquismo mexicano, O'Gorman analiza las dos posi-

\footnotetext{
${ }^{2}$ Martín Quirarte es uno de los que comparte la hipótesis, según la cual, cuando se juzga la etapa de la intervención francesa y del imperio, se tienen reservas y no pocos prejuicios. Aun hay, afirma este autor, quienes quisieran arrancar ese fragmento de la historia nacional. Quirarte, Historiografia, 1993, p. 205.
} 
bilidades del ser nacional mexicano para constituirse -como habitante de un país independiente-, como monárquico o como republicano. Su análisis nos parece pertinente, $y$ tanto más su conclusión, que apunta a señalar que el triunfo de Juárez en 1867 significó para México la victoria de la posibilidad de ser republicano sobre la de ser monárquico. Es más, la muerte definitiva de la herencia colonial de Nueva España, al menos en cuanto a sistema político se refería. Según el análisis de las grandes estructuras políticas, la visión de O'Gorman sobre el segundo imperio y su estudio en relación con la contradicción manifiesta entre la corriente monarquista hispana y el monarquismo constitucional del archiduque, ${ }^{3}$ es apropiada. Pero si miramos y analizamos el periodo bajo la óptica de la historia social, específicamente la dinámica establecida entre algunas comunidades indígenas y Maximiliano a propósito de sus reclamos por titulación y tenencia de la tierra, hay que matizar la contradicción señalada por O'Gorman.

Como sabemos, Maximiliano dirigió los destinos de su imperio dentro de un marco y una orientación liberales. Su adhesión al proyecto de la Reforma fue parte central de la crítica que le hicieron los conservadores tradicionalistas, Arrangoiz entre ellos. Sin embargo, el programa social que estableció el segundo imperio para las clases menesterosas, ${ }^{4}$ como se conocían en la época, hace suponer que, 83.

${ }^{3}$ O'Gorman, Supervivencia, 1969, pp. 82-

"Durante el siglo xix era muy usada la expresión "clase menesterosa". Se usaba para en este aspecto (y no en otros en donde se conservó el ideario monárquico constitucional del archiduque), Maximiliano se acercó a la monarquía hispana tradicionalista que medio siglo atrás había imperado en Nueva España.

Una buena parte de las comunidades indígenas -desde una perspectiva e intereses completamente diferentes a los expuestos por la elite comprometida con el proyecto del segundo imperio-, notaron que el cambio de la república por el imperio les favorecía. Lejos de la corte y de las componendas políticas, estas comunidades se hicieron una imagen del emperador por la que creyeron que sus necesidades y padecimientos terminarían con el restablecimiento de la monarquía. Nuestro punto de partida es que, en buena parte de las comunidades indígenas, hubo un "imaginario monárquico" y una represen. tación mental del emperador que la tradujo en una figura paternal y salvadora, la cual les permitía recordar

designar un amplio sector de la sociedad que, viviendo en zonas rurales y urbanas, no disponía de los recursos necesarios para sulssistir. Además de ello, se trataba de grupos sociales que, no teniendo una vía de acceso directo a la ley, clamaban primero por justicia y, segundo, por una pronta resolución a sus problemas. Revisando los expedientes del ramo Junta Protectora de la Clase Menesterosa, del Archivo General de la Nación -en adelante citado como AGN-, pudimos constatar que las solicitudes presentadas las firmaban, desde las comunidades indígenas, hasta inválidos, madres solteras, viudas y ancianos. Aclaramos que en este trabajo nos centraremos solamente en las representaciones que algunas comunidades indigenas presentaron a las autoridades del II imperio. 
los "buenos tiempos" del régimen colonial español. Buenos éstos en el sentido de que, durante ese periodo, los indígenas habían gozado de un estatus especial que en algo los había protegido de su condición de subyugados, e igualmente contra los desmanes cometidos en Nueva España, tanto por los representantes del rey como por otros sectores sociales. La llegada del emperador Maximiliano despertó, en algunas de estas comunidades, la esperanza de encontrar, por medio de él, un mejor rumbo a su deplorable situación social. Esta esperanza puesta por muchas comunidades indígenas en el emperador, ha dado lugar a que la historiografía mexicana desarrolle un tipo de análisis que ve, en las acciones del emperador y de la Junta Protectora de la Clase Menesterosa, un cierto indigenismo. ${ }^{5}$ Nosotros nos inscribimos en esta línea de trabajo.

A manera de hipótesis planteamos que, frente a la arremetida que sufrieron las comunidades indígenas en

\footnotetext{
${ }^{5}$ Los representantes de esta corriente historiográfica son González y González, "Indigenismo", 1965; Arenal, "Protección", 1991; Meyer, "Junta", 1993. Recientemente apareció el artículo de Pani, "Verdaderas", 1998, en el cual se examina la política indigenista de Maximiliano a través de la visión que tuvo el emperador, $y$ sus colaboradores, de los indígenas. Esta autora habla de un proyecto indigenista diseñado por Maximiliano, del cual formaron parte proyectos como el estudio de la problemática indígena por medio de un comité, presidido por Francisco Villanueva; la Junta Protectora de las Clases Menesterosas; el estudio de Francisco Pimentel, encaminado a establecer las causas que habían originado la deplorable situación de las comunidades indígenas, y la legislación agraria.
}

contra de sus tradiciones, particularmente en cuanto a la propiedad comunal de la tierra, la misma comunidad percibió, en el proyecto político de Maximiliano, una solución a sus necesidades de recuperación y titulación de la propiedad agraria. Para sustentar sus representaciones y reclamos acudieron al "imaginario monárquico" construido durante el régimen colonial. Además de ello, percibieron en la figura del emperador una cierta reminiscencia del régimen colonial, es decir, sobre la "benéfica" relación que durante dicho periodo había existido entre el rey y las comunidades. No en cuanto a que sc echaran atrás las medidas de desamortización de las tierras comunales, sino que, a través de la figura del emperador como protector y padre de la nación mexicana, tal y como se lec en muchas de las representaciones enviadas por algunas comunidades a Maximiliano, y dentro del marco jurídico creado por las leyes de Reforma, los indígenas tuvieran la oportunidial de defender la posesión de la tierra y de acceder a su titulación. Aclaramos que, dadas las características paternalistas y de sociabilidad tradicional existentes en el México del siglo pasado, la figura de "protector" y "padre" se hizo extensiva no sólo hacia el emperador, sino a todo aquel que, liberal o conservador, republicano o monárquico, ostentara una alta posición en el manejo del poder y de la autoridad. En el caso del emperador, esa figura paternalista se hizo más evidente. Illo lo afirmamos pensando que, en el imaginario colectivo y en la memoria histórica de las comunidades inclígenas 


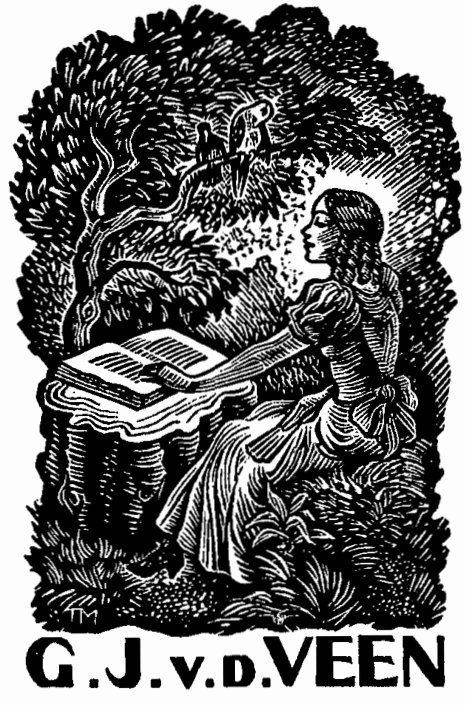

- dada su experiencia colonial-, la figura de un emperador se traducía en la de un padre bondadoso y justiciero.

Desde los tiempos de la conquista, los Austria, y luego los Borbones, dirigieron siempre una mirada paternal hacia sus súbditos indígenas acompañada de una legislación especial para las comunidades, que las protegió otorgándoles un estatus especial dentro de la sociedad colonial. Esta tradición, a pesar de los cambios introducidos por la independencia y las Leyes de Reforma, permaneció viva en la mentalidad de las comunidades, y a ella acudieron para sustentar los reclamos y peticiones dirigidos al emperador. Por otro lado -como casi todo emperador y rey, apegado a una tradición monárquica paternalista-, la de
Maximiliano era una mirada condescendiente para sus súbditos más desvalidos. Y en el caso del segundo imperio, la creación de una Junta protectora de sus intereses, formada $a$ instancias del emperador, es una prucba de ello.

LA COMUNIDAD INDÍGENA Y LA POIITICA AGRARIA DEL II IMPERIO EN EL. CONTEXTO DE LA HISTORIA AGRARIA MEXICANA DEL SIGLO XIX

Los problemas de carácter agrario que afrontaron las comunidades indígenas a partir de la segunda mitad del siglo XIX y aun desde la independencia, hay que contextualizarlos en el marco histórico general que vivieron las estructuras socioeconómicas y políticas del mundo occidental a partir de la revolución francesa. len lo que respecta a los indígenas mexicanos, estos cambios, introducidos con la independencia, los elevó a la categoría de ciudadanos, sujetos de libertad, potencialmente propictarios y jurídicamente iguales al criollo y al mestizo. Y puesto que la realiclad era otra -la libertad, la igualdad y la ciudadanía no fueron otorgadas al indígena-, podemos hablar en este caso de lo que Barrington Moore ha enunciado como "el conflicto de principios durante la modernización". ${ }^{6}$ Apli-

\footnotetext{
${ }^{6}$ Moore, Injusticia, 1996, pp. 131-137, desarrolla la noción de "el conflicto de principios durante la modernización", en relación con las tensiones que se presentaron en los gremios de artesanos alemanes (revolución de 1848), suscitadas a raíz de la penetración, en la
} 
cado este el concepto a la situación mexicana del siglo XIX, diremos que se trataba de un proyecto liberal y que uno de sus fines era que la sociedad criolla terminara con los privilegios heredados de la sociedad colonial para poder emprender la búsqueda del progreso. Tal proyecto tuvo una fuerte oposición, tanto de algunos sectores conservadores de la sociedad, como de las comunidades indígenas. Al ver que en él sus intereses eran atacados, las comunidades indígenas optaron, en muchas ocasiones, por la lucha frontal contra el nuevo orden de cosas, pero también -a través de peticiones dirigidas a las autoridades- denunciando las injusticias y el agravio moral que el nuevo orden jurídico les estaba infligiendo. La moral tradicional de las comunidades, uno de cuyos fundamentos era la propiedad comunal sobre la tierra y la pertenencia del individuo a la comunidad y no a un Estado nacional, entró en serio conflicto con la nueva moral capitalista. El nuevo orden hablaba de propiedad privada; de libre oferta y demanda de la tierra; de ciudadanos e individuos libres de ataduras corporativas y pertenecientes a una entidad mayor llamada México. La

estructura económica, de la ética capitalista. Más exactamente, en este concepto Moore explica cómo la conformación de la sociedad industrial capitalista moderna en Europa occidental generó cambios en el contrato social. Tales cambios, afirma este autor, fueron el resultado de un conflicto entre los portadores y portavoces de los viejos y de los nuevos principios de la desigualdad social. Ésta fue 1a situación que enfrentaron los principios 1 berales introducidos en México desde la independencia.

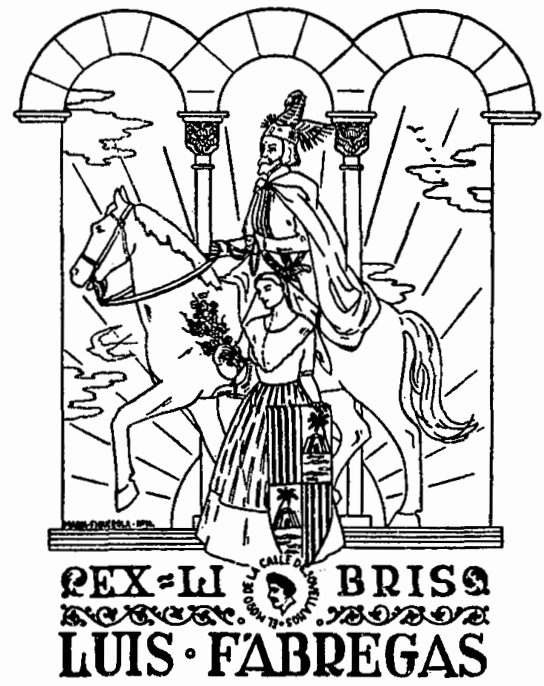

ética de las comunidades era colectiva, en tanto que la del capitalismo cra individualista y hacía énfasis en las virtudes de la competencia, del libre mercado, del potencial desarrollo ciel individuo como tal y de la igualdad de todos los hombres. La realidad, sin embargo, era otra. Las comunidades indígenas estaban -como aún hoy-, haciendo acto de presencia en buena parte del territorio nacional, con toda su carga cultural y su propia visión del mundo, y no parecían muy dispuestas a adoptar el nuevo estilo de vida que les imponía la sociedad mayoritaria. Por el contrario, como lo acota Jaime del Arenal,

parecía que terca y neciamente se aferraban a unas costumbres y a un tipo de sociedad comunitaria que contradecía 
cle plano aquel modelo, al cual tanto aspiraban nuestros liberales y buena parte de nuestros conservadores. ${ }^{7}$

El tono suplicante de las representaciones que a continuación analizamos, mismas que fueron presentadas por las comunidades indígenas al emperador Maximiliano y a la Junta Protectora de las Clases Menesterosas, no es único y exclusivo del periodo que estudiamos. Dados los rasgos patriarcales autoritarios propios de las sociedades rurales, a los cuales México no escapó durante el siglo XIX y aun bien entrado $\mathrm{el} \mathrm{xx},{ }^{8}$ este tono de súplica con que los sectores populares escribieron sus representaciones a las autoridades fue una constante a todo lo largo de la centuria. Lo que queremos sugerir es que este tipo de discurso, que aparece en las representaciones dirigidas por las comunidades indígenas a Maximiliano, a Juárez, a Porfirio Díaz y a otros líderes prominentes de la política nacional, trasluce un tono, a manera de "ruego", que elevaba a estos personajes a la categoría de "padres" todopoderosos, a los cuales había que dirigirse muy comedida y "religiosamente" a la hora de solicitarles ayuda y protección. Por varias razones, creemos que las cartas enviadas a Maximiliano lo confirman, pues acentuaban estas características de la figura paternal, con una recurrencia a exaltar no solamente su pa-

${ }^{7}$ Arenal, "Protección", 1991, p. 4.

${ }^{8}$ para el caso mexicano, esta dinámica social, rural-paternalista y clientelista, ha sido estudiada por Guerra, México, 1985, en lo que él enuncia como las sociabilidades tradicionales. ternalismo, sino su providencialismo, su bondad y su proclividad a impartir justicia. Además, todo ello iba acompañado de la reverencia, la sumisión y la obediencia debida a un empcrador.

Otro aspecto importante a clestacar, tendiente a no descontextualizar el segundo imperio, tiene que ver con la continuidad presente en éste y en el periodo de la Reforma, en lo que tuvo que ver con el proceso de desamortización de los bienes comunales. Al respecto Jaime del Arenal afirma que, cuando menos desde su establecimiento hasta julio de 1866 , "no se puede desconocer el carácter liberal del segundo imperio, el cual, en varios aspectos, fue incluso más allá del liberalismo de los republicanos". Siguiendo los planteamientos de este autor, diremos que ante el problema de las comunidades indígenas en cuanto al proceso de desamortización de la ticrra, el segundo imperio se diferenciaría del liberalismo republicano impulsado por los gobiernos de Juárez, Lcerdo y Porfirio Díaz

acercándose, paradójicamentc, tanto al proteccionismo de la legislación indiana como a las ideas protectoras del proletariado rural y urbano, propucstas por algunos socialistas utópicos curopeos, muy difundidas entonces en Europa y América. ${ }^{10}$

En relación con el tipo de política agraria adoptada por Maximiliano, Jean Meyer es más radical que Arenal, pues afirma que Maximiliano y Carlota "recogen, en cierta medida, la tradición

9Arenal, "Protección", 1991, p. 3.

${ }^{10} \mathrm{Ibid}$., p. 6. 
de los virreyes"; en este contexto, continúa diciendo Meyer, Maximiliano "se configura más como déspota ilustrado que como liberal". Meyer está de acuerdo en que, ciertamente, Maximiliano de Habsburgo "hizo suyo el proyecto liberal de una nación de ciudadanos-propietarios. Por eso afirmó el cumplimiento de las leyes de desamortización. En este sentido no cabe duda de que era un liberal." ${ }^{11}$ Nosotros preferimos adoptar el punto de vista de Arenal, es decir, pensar que nuestro personaje, paradójicamente, apostó tanto al proteccionismo de la legislación indiana, como a las ideas protectoras emanadas del socialismo utópico.

Es importante señalar, como lo ha hecho Meyer, que el indigenismo del archiduque derivó de la tradición patrimonial de los Habsburgo, de los cuales era descendiente, y del conocimiento que podía tener de la cuestión agraria del imperio austrohúngaro, muy parecida a la mexicana. De ahí que, como lo afirma Arenal, manifestara "una capacidad de comprensión, condolencia, equidad y elemental justicia" ${ }^{12}$ En relación con la propiedad comunal de la tierra, tanto Maximiliano como la Junta Protectora de las Clases Menesterosas tuvieron una política ecléctica, que iba del proteccionismo de la legislación indiana a las nacientes ideas protectoras del proletariado rural y urbano, en boga en Europa, pasando por el liberalismo. De la vuelta a la tradición hispana dan cuenta las

\footnotetext{
${ }^{11}$ Meyer, "Junta", 1993, pp. 329-330.

${ }^{12}$ Ibid., p. 330 y Arenal "Protección", 1991, p. 16 , respectivamente.
}

leyes del 5 de julio y 15 de septiembre de 1865 , en que se restituyó la personalidad jurídica a las comunidades indígenas y se reconoció su derecho a la posesión de las tierras de comunidad. También la ley del 1 de noviembre del mismo año, en que se concedió la libertad a los peones. Esta ley, scr̃ala Meyer, siguió los lineamientos generales del bando promulgado por el virrey, conde de Gálvez, el 23 de marzo de 1783. Las leyes de 1866 hablan de dotar de tierras a las comunidades indígenas que carecían de ellas. lin el reglamento de trabajo para las fábricas del imperio se dejan ver las ideas protectoras del trabajador rural y urbano, muy en boga en la Europa de Proudhon. ${ }^{13}$

El regreso a la legislación monárquica hispana, y el eclecticismo al que hacemos referencia, se palpa muy bien en un proyecto que, sobre "división y adjudicación de terrenos de común repartimiento" presentó, ante el Ministerio de Instrucción Pública y Cultos, la Junta Protectora de las Clases Menesterosas el 4 de agosto de 1865. En un tono muy liberal y pragmático, la Junta señaló que

cra necesario e indispensable inclividualizar la propiedad en común cle los pueblos, reclucirla a particular para crear en

${ }^{13}$ Estas leyes se pueden consultar en Colección, 1865. El reglamento de trabajo para las fábricas del imperio, en AGN, Junta l'rotectora de las Clases Menesterosas, vol. V, exp. 11, fs. 88-94. Afirma Meyer, "Junta", 1993, p. 356, que el liberalismo social del emperador, no se diferenciaba del que defendía Ponciano Arriaga, autor del voto particular sobre la propiedad y de la propuesta de crear "procuradores de los pobres". 
la masa general de nuestra población esos pensamientos de orden y previsión, esos sentimientos de moralidad, de libertad e inclependencia personal.

Al referirse a la legislación indiana, recordaba que los terrenos que constituían los ejiclos, propios, pastos y baldíos habían sido, en su mayor parte, de uso común. Más adelante señaló que, para proteger la propiedad territorial de las comunidades "de la codicia y continuas usurpaciones de la raza dominadora", se había mandado desde los tiempos de Felipe II hasta las ordenanzas de intendente "que, ante todas cosas, se reservara lo necesario para plazas, ejidos, propios, pastos y baldíos de los lugares y comejos poblados". Pero lo interesante a resaltar es la reflexión que hizo la Junta en relación con que, ante leyes tan expresas y terminantes,

no puede menos que llamar fuertemente la atención y causar mucha extrañeza el encontrar infinidad de poblaciones que no tienen ya ni siquiera el fundo legal, tan necesario para su existencia y conservación.

Luego muy pertinentemente señalaba: "Esto indica que los mandatarios españoles, o no cumplieron con la prevención de la corona permitiendo enajenar tierras que no podían serlo, o que éstas se encuentran usurpadas." Al parecer la Junta creyó que era más lo segundo. Explicó que dado el derecho ancestral de las comunidades sobre la tierra,

al comenzarse la independencia de nuestra patria, esa propiedad debió pasar al dominio pleno y absoluto de los pueblos, y debe ser tan sagrada y respetada como cualquiera otra legítimamente adquirida.

Más adelante expresó que, en varios puntos de la república, se había abusado de la ignorancia de los indios y de su situación miserable, "y muchos codiciosos, por medio de denuncias, se hicieron propietarios o aumentaron sus posesiones, adjudicándosc los terrenos de aquéllos". Pero también se apoyó en la Ley Lerdo para sustentar los derechos que, en materia territorial, asistían a las comunidades.

Tan cierto y evidente es que los indios tienen derecho de propiedad sobre las tierras de comunidad y repartimiento, y que no están obligados a ninguna prestación pecuniaria o servicio personal, que el mismo autor de la ley de 25 de junio de 1856 reconoció explícitamente ese derecho y la libertad en que estaban sus poseedores de toda clase de gravamen.

Solicitó la Junta que se dicra a los indígenas

la seguridad de que ninguna persona ni autoridad puede privarlos del goce de sus tierras y de que pueden transmitirlas a sus herecleros y venclerlas bajo ciertas condiciones, y esto será bastante para hacerlos apreciar debiclamente la posesión de la propiedad particular. ${ }^{14}$

\section{JUSTICIA Y PROVIDENCIALISMO A IA II.EGADA DE MAXIMILIANO}

Una vez que Maximiliano y Carlota arribaron al puerto de Veracruz, el 28 de mayo de 1864 , las manifestaciones

${ }^{14}$ AGN, Gobernación, legajos vol. 1144 (1), exp. 1 . 
de apoyo de una buena parte de los sectores que conformaban la sociedad mexicana de la época se hicieron presentes. Tanto en las crónicas periodísticas, como en los relatos de autores contemporáneos al suceso - unas y otros se citan más adelante-, resalta el hecho de que la llegada de sus majestades imperiales causó furor y fue motivo de fiesta. Por razones obvias, el grupo liberal republicano no participó en dichas celebraciones; por el contrario, mientras la monarquía se instauraba, 21 de ellos con Juárez a la cabeza, iniciarían su periplo por el país con la república a cuestas.

Como ocurriría con la entrada de Juárez a la ciudad de México en 1867, cuando Maximiliano hizo lo propio hubo fuegos artificiales, flores, poemas, balcones y ventanas adornados con vistosas colgaduras, comitivas especiales, salvas de cañón, arcos, discursos y recibimiento masivo de la población. ${ }^{15} \mathrm{Al}$ parecer, y de acuerdo con las crónicas de la época que dan cuenta del viaje que de Veracruz condujo a los monarcas a la capital del imperio, fue numerosa y variada la población que se hizo presente a lo largo de todo el camino. Nos interesa destacar la comparecencia y el tipo de actitud que algunas comunidades indígenas tuvieron para Maximiliano,

\footnotetext{
1s Quizá las mejores crónicas que dan cuenta de la entrada del emperador a la ciudad de México sean Advenimiento, 1864 y Miramar, 1864. Un relato menor es el que hace Hidalgo, Proyectos, 1904, pp. 260-271. Por su parte, Blassio, Maximiliano, 1905, pp. 1-6, hace una breve descripción de la entrada de los emperadores a la ciudad de México.
}

e igualmente la posición que éste asumió frente a sus súbditos indígenas, en el entendido de que entre uno y otros surgió una cierta atracción. De parte de las comunidades se hizo manifiesta la de ver al emperador como padre y salvador; en el archiduque, el hecho de que percibió a los indígenas como uno de los sectores sociales más sufridos y necesitados de su imperio.

Al parecer el primer encuentro significativo de los emperadores con indígenas mexicanos tuvo lugar al día siguiente de que los mismos arribaron a la población de Córdoba. Y fue en ocasión de que Maximiliano invitó a su mesa a dos indios, el alcalcle de Amatlán y el de Calcahualco.

De esta manera el monarca -en cl decir del diario El Pájaro Verde-, inició a la raza indígena en las distinciones con que ha de tratarlos el imperio. Las poblaciones indias de 30 leguas a la redonda lo saben ya, y están encantadas. ${ }^{16}$

Esta especie de encantamiento de las comunidades indígenas ante la llegada de un emperador, fue planteada por Arrangoiz. Afirma este autor que ninguno de los sectores de la sociedad recibió a Maximiliano "con más entusiasmo que los indios". Creían -afirma este autor-, que el gobierno imperial

pondría término a la tiranía a que estaban sujetos, a pesar de ser ciudadanos en el pleno ejercicio de sus derechos. [...] Las tradiciones y, en no poco, los recuerdos de la paternal legislación española, fueron los que hicieron que los

${ }^{16}$ El Pájaro Verde, núm. 276, 6 jun. 1864. El relato también aparece en Miramar, 1864, p. 94 . 




indios recibieran con entusiasmo tan grande a Maximiliano. ${ }^{17}$

Con el correr del tiempo y, sobre todo, cuando las comunidades presentaron al emperador su problemática agraria, particularmente la defensa y la

${ }^{17}$ Arrangoiz, Apuntes, 1869 , p. 192. En términos parecidos se pronunció El Pájaro Verde, sólo que en clara posición partidista habló "de las mentiras y desprecios con qque -se refería a los indígenas- los ha oprimido la república durante cuarenta años", núm. 276, 6 jun. 1864. También en la crónica del viaje de SS. MM., Miramar, 1864 , p. 121 , se afirma que de todos los habitantes de la comarca de Orizaba, "los indios fueron los que experimentaron un gozo más cabal con la llegada de los emperadores". posesión de la tierra, éste mostró entusiasmo por mejorar sus condiciones de vida y mucho más, cuando arribó a la corte. En el siguiente apartado veremos cómo todo el sentimiento de esperanza, apoyo, adhesión y entusiasmo mostrado por los indígenas a la llegada de sus majestades iba enfocado a reclamar la posesión y la defensa de sus tierras, y cómo Maximiliano respondió positivamente a muchas de las peticiones. ${ }^{18}$ Mientras tanto, llegados los emperadores a Orizaba hubo un nuevo encuentro con la comunidad indígena de la región, donde también se hizo patente la esperanza de los naturales en que Maximiliano les solucionara sus problemas más urgentes, los del sustento por su tierra. Aquel día, de acuerdo con uno de los relatos de la época, hubo una escena "digna de los tiempos patriarcales". El cura del Naranjal se presentó ante los emperadores con el alcalde, un regidor de aquel pueblo de indios, dos vecinos que tenían el cargo de topiles (alguaciles a las órdenes de los jueces) y dos indias. El alcalde se dirigió a Fernando Maximiliano en náhuatl; la traducción ofrecida por las crónicas de la época dio la siguiente versión:

Nuestro honorable emperaclor: aquí tienes a estos pobrecillos inclios hijos tuyos, que han venido a saluclarte y a que sepas que les alegra mucho el co-

${ }^{19}$ En efecto, a través de la creación de la Junta Protectora de las Clases Menesterosas, el emperador respondió -en muchos casos- afìrmativamente a los problemas de tierra presentados por las comunidades. Del urabajo adelantado por la Junta en favor de las comunidades indígenas, ver Meyer, "Junta", 1993, pp. 137 y 342-356. 
razón tu venida; porque en ella ven a manera de un arco iris que desbarata las nubes de discordia que parece se habían avecinado en nuestro reino. El Todopoderoso es el que te manda: que él te clé fuerzas para que nos salves. Aquí está esta flor: mira en ella una señal de nuestro amor: te la dan tus hijos clel Naranjal.

En la cita destaca el tono providencial con que el alcalde se dirigió a Maximiliano. El archiduque contestó en los siguiente términos, mismos que, según el relato de la época, fueron traducidos a los indios en su lengua:

Me es muy grato, mis queridos hijos, recibiros en comisión de vuestro pueblo; porque es una prueba de la confianza que debéis poner en mí para lograr la paz y el bienestar de que tanto habéis carecido.

Podéis contar con el solícito empeño que tomaré para proteger vuestros intereses, fomentar vuestras labores y producciones agrícolas y mejorar en todo vuestra situación, y así podéis anunciarlo a los habitantes del Naranjal. ${ }^{19}$

También es de notar el tono paternal con que el archiduque responde. Al dirigirse a clases menesterosas y además indígenas, Maximiliano, en su carácter de emperador, acentuó en su discurso el tono paternalista propio de la época. Y, andando la monarquía, ese carácter providencial que las comunidades atribuyeron al imperio

${ }^{19}$ Las alocuciones en idioma náhuatl y en español aparecen en Miramar, 1864, p. 115. Los discursos aludidos también fueron publicados en El Pájaro Verde, núm. 277, 7 jun. 1864, $y$ en Advenimiento, 1864, p. 198.



- entre otros aspectos- sería utilizado por ellas para basar sus concepciones del mismo.

Magnanimidad, justicia, mirada benevolente y paternal, esperanza de la comunidad en el rey, serían, en consecuencia, algunas de las expresiones que aparecerían en muchas de las representaciones dirigidas por las comunidades al emperador. Estas dan sustento a nuestra hipótesis del providencialismo. Así, por ejemplo, la solicitud llegada al emperador (agosto de 1864), proveniente de la comunidad de Tepoztlán, aludía a su providencialismo: "Siendo como sois dignamente el soberano que la Providencia ha destina- 
do para remediar los males que afligen a los pueblos". En la solicitud que, por medio del cacique Gregorio Cordero, presentó la comunidad de Santamaría (Zapopan-Guadalajara) al emperador en septiembre de 1865 , se daba un "voto de gracias al Todopoderoso por el beneficio que nos ha hecho de que unos príncipes amables y carińosos aceptaran con gusto el trono de México [...] sólo con el interés de salvar a nuestra patria". Los vecinos del pueblo de Nexquipaya (Texcoco) fueron más explícitos en cuanto al providencialismo de Maximiliano: refiriéndose a él, afirmaron en su solicitud de diciembre de 1865 que "la Providencia Divina lo ha conducido a este país para consuelo del afligido, oyendo y escuchando sus lamentos". ${ }^{20}$

En el largo trayecto que realizaron Carlota y Maximiliano de Veracruz a la ciudad de México, quizá uno de los sucesos más significativos en relación con la forma en que los indígenas percibieron su llegada, sea la coronación del archiduque hecha por los indígenas de las cercanías de Orizaba. En una pequeña nota, El Pájaro Verde dio cuenta del evento:

Los indios quisieron coronar a S. M. el emperador que accedió a sus deseos: los hijos del pueblo de Zoquitlán y Barrio Nuevo habían formado un trono verdacleramente indígena, adornado con figuras caprichosas de cucharilla y flores silvestres, sus majestades se

${ }^{20}$ AGN, Gobernación, legajos vol. 1144 (1), exp. 1; Gobernación, legajos vol. 1144 (1), exp. 2 y Junta Protectora de las Clases Menesterosas, vol. III, exp. 21, f. 323v. sentaron y, entonces, una de las autoridades ciñó una gran corona al emperador. $^{21}$

Aunque la información no permite una amplia interpretación del suceso dado que no ahonda en detalles, según la perspectiva de nuestro análisis este evento es muy significativo. Permite inferir que, para los indígenas, al menos para los que participaron de la referida coronación, el emperador era un personaje que, a la manera de los virreyes de Nueva España, podía remediar sus problemas.

En el por entonces departamento de Puebla y, más exactamente, en la población de Cholula, los habitantes -indígenas casi todos, de acuerdo con una crónica de la época-, recibieron alborozados a sus majestades. Entre Puebla y Cholula, según la misma crónica, los indígenas habían construido más de quinientos arcos de ramos y flores:

de tramo en tramo aparecían comparsas de indígenas con tambores y chirimías, y acompañaban a SS. MM. tocando, hasta ser reemplazadas por nuevas comparsas. Las sonatas, los cohetes, las detonaciones de las cámaras |mortero para salvas] y los gritos de entusiasmo no cesaron en todo el camino. ${ }^{22}$

Al parecer, estas escenas se repitieron en la travesía que faltaba para llegar a la ciudad de México. Desde Río Frío hasta la hacienda de Zoquiapan -en este último punto Maximiliano pasó la noche antes de su entrada en

${ }^{21}$ El Pájaro Verde, núm. 278, 8 jun. 1864.

${ }^{22}$ Miramar, 1864, pp. 183-184. 
México-, informó El Pájaro Verde, "los pueblos del tránsito preparan arcos y enramadas y las músicas de los mismos pueblos vendrán tocando por el camino". ${ }^{23}$

La entrada a la capital del imperio se verificó el 12 de junio de 1864. Afirma José María Hidalgo que, además de la población de México -unos 200000 habitantes para la época, de acuerdo con este autor-, contemplaron el arribo de sus majestades "multitud de gente de las provincias y millares de indios que habían venido a presenciar aquella entrada tan grande y tan espléndida". ${ }^{24}$ Poco después, el emperador inició un viaje de reconocimiento por los departamentos del centro de su imperio. De este viaje no hemos encontrado mayor información, pero al parecer, por donde anduvo, siempre fue bien recibido. Al menos así lo hace saber el prefecto superior político y comandante militar de Tula, quien en agosto 15 de 1864 informó al subsecretario de Estado y del Despacho de Gobernación del imperio que, para satisfacción de su majestad la regenta del imperio, manifestaba que

su majestad el emperador, en su tránsito por este departamento, ha recibiclo toda clase de espontáneas ovaciones, los habitantes le han hecho palpable su amor, su respeto $y$, casi en toda la línea, han estado poblados los vientos por

${ }^{23}$ El Pájaro Verde, núm. 273, 2 jun. 1864.

${ }^{24}$ Hidalgo, Proyectos, 1904, p. 268. Otros pormenores de la entrada de Maximiliano a la ciudad de México, se pueden leer en Miramar, 1864, cap. 9 y Advenimiento, 1864, cap. 9. cohetes, repiques, música y entusiastas vivas que le ha dirigido la multitud. ${ }^{25}$

La sensibilización de Maximiliano frente a la dura situación de las comunidades indígenas fue palpable y proveniente de una realidad que pudo percibir en sus viajes y visitas al México rural. En una carta donde el presidente de la Junta Protectora de las Clases Menesterosas, Faustino Chimalpopoca, comentaba los abusos cometidos en la Huasteca contra los intereses de las comunidades, recordaba que:

Afortunadamente, nuestro ilustre so-
berano lo sabe todo, pues que infatiga-
ble, visitando a las ciudades, villas, pue-
blos y barrios, lo ha visto palpablemen-
te y comprenclido su causa mejor que
otro alguno.

Este convencimiento de Chimalpopoca en relación con los buenos propósitos indigenistas de Maximiliano, ya había sido expresado en una proclama que, leída "en idioma azteca a la raza india", había dirigido este personaje a la "raza india y pueblos todos" en octubre de 1863. En ella, después de resaltar la importancia del segundo imperio, que calificó como justo, ya que era el establecimiento de la religión, exhortaba a las comunidacles a adherirse al mismo "porque veo que, por medio de él, la adorable Providencia Divina mejorará nuestra suerte". ${ }^{27}$

El recibimiento a sus majestades en las diferentes estaciones de su viaje de

\footnotetext{
${ }^{25}$ AGN, Gobernación s.s. caja. 505, exp. 9.

${ }^{26} \Lambda \mathrm{GN}$, Junta Protectora de la Clases Menesterosas, vol. v, exp. 14, f. 107.

${ }^{27}$ Citado en Zamacois, Historia, 1880, documento núm. 8 del anexo, p. 1054.
} 
Veracruz a la ciudad de México, sólo es comparable al que se le hacía a los virreyes de Nueva España cuando, una vez que arribaban al puerto, emprendían este mismo recorrido. El boato virreinal, en aquella época, e imperial en los tiempos del archiduque, con toda su fastuosidad y representación, ha debido suponer para las comunidades indígenas algo así como la llegada de un dios, de la esperanza, de un padre salvador y magnánimo, en una palabra, de la Justicia. La comparación del viaje que, tanto Maximiliano como los virreyes tenían que hacer obligadamente entre Veracruz y México, la hacemos después de haber leído una breve descripción del recorrido realizado por el virrey Carlos Francisco de Croix. ${ }^{28}$ En ella se puede apreciar en algo el regocijo con que muchas de las comunidades indígenas recibieron a este dignatario. Algo de ello habría quedado en la representación mental de las comunidades que se manifestaría ante la figura de Maximiliano.

En el imaginario monárquico de una buena parte de las comunidades indígenas del siglo pasado, había pues un cierto reconocimiento y veneración por la figura del rey. Si pensamos en la coyuntura anterior de la invasión napoleónica a España y en los sucesos que de ella se derivaron, particularmente en la forzosa abdicación al trono de Fernando VII hijo de Carlos III en favor de los hermanos Bonaparte, se puede apreciar la misma lealtad, manifestada al monarca destituido, en muchas partes del territorio

${ }^{28}$ Ver Croix, Instrucción, 1960, pp. 8-9. de la entonces Nueva España. En estas demostraciones estuvieron presentes también muchas comunidades indígenas. En recientes estudios, Marco A. Landavazo ha dado asimismo importancia a esta participación de los indígenas en las manifestaciones de lealtad y cariño al "Deseado", Fernando VII. La hipótesis de Landavazo es que, tales manifestaciones, no fueron meramente de palabra, de carácter político o moral, sino que se acompañaron de aportaciones de tipo económico. ${ }^{29} \mathrm{Y}$ afirma este autor que, posiblemente, estas aportaciones de los indígenas a la causa de la corona española fueron realizadas por presiones de algún cura o funcionario real. Sin embargo, llega a la conclusión de que estos donativos fueron, no obstante, hechos por los pueblos indígenas obedeciendo a un profundo sentimiento de lealtad. Señala igualmente que tales manifestaciones aparecen como una muestra clara de la importancia de la figura del rey entre los indígenas. ${ }^{30}$ En lo que respecta a sus comunidades, esa centralidad del monarca coincidía con la de la noción de justicia. En este sentido hay que señalar que, al analizar el Juzgado General de Indios, Woodrow Borah concluye que la institución reforzó la idea del monarca como un dador de bondad y justicia, frente a la

\footnotetext{
${ }^{29}$ En su estudio sobre los préstamos novohispanos realizados a la corona española a raíz de las guerras con Inglaterra y Francia durante las últimas décadas del siglo Xvir, Marichal, "Guerras", 1990, reseña los donativos realizados por las poblaciones indígenas del virreynato.

${ }^{30}$ Landavazo, "Exacción", 1996 y "Vuestra", 1997.
} 
apremiante situación de explotación de los naturales en Nueva España. ${ }^{31}$

La reflexión que introducimos en el anterior párrafo la hacemos para confirmar que, en la memoria histórica de las comunidades, pervivieron algunos elementos de antiguo régimen que, ante la figura del emperador, fueron expuestos y recreados nuevamente, y que se puede apreciar en ellos un imaginario indígena monárquico. Esa memoria histórica pervivió, a pesar de la independencia y de las Leyes de Reforma-de todas las medidas de modernidad política y económica que de estos dos procesos se desprendieron-, y se hizo manifiesta cuando Maximiliano asumió como emperador de México. En ello, nos parece, hay una motivación central que indica lo que, para las comunidades indígenas, representaba la figura del rey como portador y otorgante de justicia. Con ello no queremos afirmar que, sólo durante el II imperio, las comunidades hubieran clamado por justicia y que únicamente durante este periodo se les hubiera otorgado; sino ese elemento de antiguo régimen que, pese al Estado de derecho que se intentaba introducir y construir en esa época-pensemos, por ejemplo, en que ese Estado de derecho anterior, antes que a impartir justicia, se apegaba al dictamen de la ley- y pese también al acendrado liberalismo de Maximiliano, funcionó y, hasta cierto punto, fue benéfico para dar solución a los problemas de defensa y titulación de la tierra presentados por las

${ }^{31}$ Borah, Juzgado, 1985, ver especialmente pp. 381-407. comunidades a la Junta Protectora de las Clases Menesterosas.

\section{REGOCIJO E IDENTIFICACIÓN}

CON BL IMPERIO

Con anterioridad hemos dejado establecido que hay, entre los estudiosos del segundo imperio, una corriente historiográfica claramente indigenista, la cual ve, en las acciones de Maximiliano hacia los indígenas -específicamente el proyecto agrario-, un cierto retorno a la tradición jurídica colonial. Los más claros exponentes de esa avenida de investigación han sido Jaime del Arenal y Jean Meyer. Meyer, por ejemplo, habla de que Maximiliano y Carlota recogen, en cierto modo, la tradición de los virreyes ${ }^{32}$ Erika Pani realiza un análisis parecido, tomando en cuenta la mirada y la percepción que de las comunidades indígenas tuvieron Maximiliano y su grupo de asesores. En gran medida, estos tres autores han sustentado sus hipótesis en el análisis de la legislación agraria sancionada por el emperador y en las medidas que tomó la Junta Protectora de las Clases Menesterosas. Como complemento a los argumentos y los análisis de estos dos autores, nosotros nos proponemos arribar al mismo punto que ellos -el indigenismo de Maximiliano-, a través del análisis de las peticiones, reclamos y representaciones que las comunidades clevaron al emperador por vía directa o por medio de los documentos de la mencionada Junta.

${ }^{32}$ Meyer, “Junta", 1993, p. 329. 




No podemos perder de vista que, antes y después de que el segundo imperio se hubiera establecido, una buena parte de la sociedad mexicana se movía con una dinámica patriarcal propia de las sociedades rurales del antiguo régimen, en donde muchas de las formas de relación social y de autoridad pasaban por vínculos y sociabilidades de tipo tradicional: clientelismo, parentesco y paternalismo, entre otras. En la relación que establecieron las comunidades indígenas con el emperador esa dinámica pa- triarcal se acentuó. No obstante no conocer a fondo las solicitudes que los indígenas enviaron a Benito Juárez y a Porfirio Díaz, donde esa sociabilidad de tipo tradicional también se hizo presente, intuimos que, las que nosotros estudiamos, se diferencian de aquéllas porque hay en ellas un cierto retorno al orden colonial, o quizá sea más prudente hablar de una recurrencia a la condición legal que dicho régimen otorgó a las comunidades, al menos, en cuanto a los aspectos centrales de la tenencia de la tierra. En muchas de las representaciones dirigidas por las comunidades al emperador, esa recurrencia a la propiedad como un bien comunal está presente como uno de los argumentos más contundentes.

En diciembre de 1865 los naturales y vecinos del pueblo de San Cristóbal Nexquipayac, perteneciente al distrito de Texcoco, departamento del Valle de México, enviaron una representación al emperador Fernando Maximiliano solicitando les fueran ven. didos unos terrenos y se les hiciera merced de un pedazo de la laguna de Texcoco. ${ }^{33}$ Después de exponer su situación en los términos de que el pueblo-1 200 almas-, "no tiene lugar donde ensancharse", los firmantes hacían referencia a los tiempos coloniales, cuando con "mucha sabiduría", el gobierno español, "siempre tenía en reserva tierras con el nombre de realengas [...] para dar a sus hijos, como buen padre de familia, las posesiones

${ }^{33}$ El documento reposa en AGN, Junta Protectora de las Clases Menesterosas, vol. JII, exp. 21 , ff. $317-337$. 
o sitios que necesitaban ellos". Luego hacían notar que, desde que se había consumado la independencia y hasta esa fecha, nunca habían tenido gobierno y que, si había existido, "ha sido seguramente más bien un monstruo de soberbia, o un conjunto de inmorales y usurpadores que continuamente estaban acechando las propiedades particulares y de corporaciones". A renglón seguido agregaban que creían "que V. M. I., que actualmente es nuestro padre por mil títulos, está en el caso de recobrar muchas tierras realengas que injustamente han agregado a sus propiedades muchas haciendas". Hay en esta solicitud una remembranza del orden colonial -las tierras realengas-, también se acude a la figura paternal del emperador y se hace una crítica al gobierno republicano e igualmente -aunque no explícitamente-, al proceso de desamortización de tierras comunales.

Una segunda singularidad de las representaciones que estudiamos es que, por el tipo de lenguaje que en ellas se manejaba, había un cierto clima de aceptación de la monarquía, manifiesto en la confianza que expresaban al dirigirse a la cabeza visible del imperio. No hemos encontrado, ni creo que lo haremos, un documento en donde, explícitamente, las comunidades hayan expresado su deseo de que retornara la monarquía; pero nuestra afirmación queda sustentada en el hecho de que, en las representaciones, las comunidades se regocijan de poder acudir a un emperador. Así lo expresó la comunidad de San Cristóbal Nexquipayac en su ya citada solicitud: "Ante V. M. I. con el más profun-

\section{EX-IIBRIS}

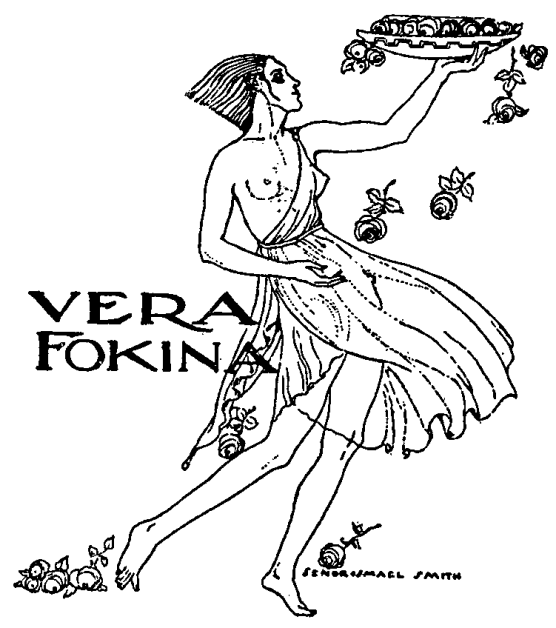

do respeto decimos: Que nunca con más júbilo ni con mayor contento, debemos darnos recíprocos parabienes que en las presentes circunstancias". En septiembre de 1865, el cacique de Santa María, distrito de Zapopan, departamento de Guadalajara, en representación de su pueblo, manifestó también este regocijo. ${ }^{34}$ Saludaba el cacique a su majestad,

${ }^{34}$ La representación está en el AGN, Gobernación, legajos, vol. 1144 (1), exp. 2. 
con el más sincero y cordial placer, [...] y los felicito dándoles en nombre de Dios y María Santísima las más fervientes gracias y los más sinceros agradecimientos por su bienvenida a nuestra patria $[\ldots]$.

La noción de justicia contenida en las representaciones de las comuni. dades indígenas, durante el segundo imperio, es otra característica que las diferencia de las solicitudes que, en otras etapas del siglo XIX, fueron dirigidas por las comunidades a figuras políticas prominentes. Uno de los reveses que afrontaron las comunidades a raíz de los cambios que trajo la modernización a partir de la consu. mación de la independencia, fue el crecimiento de injusticias, debidas al despojo de tierras, de que eran objeto. En este sentido hay que mencionar que, en casi todas las solicitudes encaminadas a reclamar la restitución de tierras, la cesión de terrenos o a expresar su renuencia a pagar por la obtención de títulos de propiedad, está presente la idea de que fue a partir de la consumación de la independencia cuando se iniciaron las calamidades de los pueblos. Así la demanda de justicia será uno de los argumentos constantes expuestos en sus peticiones. Por su parte, Maximiliano tuvo la profunda convicción de que sus súbditos -especialmente los que formaban las clases menesterosas-, necesitaban de alguien que les resolviera con justicia. Dos documentos nos dan la prueba de esta convicción: uno es la proclama que él mismo hizo a los mexicanos al llegar al puerto de Veracruz, donde les anunció que la divisa de su imperio sería "equidad en la justicia". ${ }^{35}$ Luego del viaje que realizó por algunos de los entonces departamentos del interior del país, dijo refiriéndose a la población indígena: "Atendiendo a que, en nuestro viaje al interior del imperio, hemos podido conocer las necesidades y sufrimientos de que hasta hoy han sido víctimas", ${ }^{36}$ decretó la formación de la Junta Protectora de las Clases Menesterosas. Jaime del Arenal afirma que México fue concebido por el emperador como un campo de acción y de experimentación, donde pucto desplegar la filantropía propia de la ilustración y del Estado moderno. ${ }^{37}$

Tenemos entonces que, no obstante que en cualquier sociedad donde se presentan desigualdades la gente clama justicia, dadas las condiciones sociales de las comunidades indígenas en el momento de la instauración del segundo imperio y del discurso protector de Maximiliano, la noción de justicia tuvo, durante este periodo, especial significación y recurrencia. Aquí llamamos la atención sobre el hecho de que, muy seguramente, otros grupos sociales plenamente identificados con una sociedad de la edad moderna, más que apelar a la noción de justicia, reclamarían el cumplimiento de la ley. En la ya citada petición que la comunidad de Santa María envió al emperador por intermedio de su cacique, se mencionaba

\footnotetext{
${ }^{35}$ Ver su proclama dirigida a los mexicanos una vez que arribó al puerto de Veracruz. $B l$ Pájaro Verde, núm. 272, 1 jun. 1864.

${ }^{36}$ Decreto Imperial que instituyó la Junta Protectora de las Clases Menesterosas. Colección, 1865, vol. 3, t. vi, p. 183

${ }^{37}$ Arenal, "Protección", 1991, p. 7.
} 
lo agradable de su justicia y buen gobierno que a nombre de los Cuatro Evangelios ha puesto en paz la mayor parte de nuestra nación y ha hecho un grande beneficio a los habitantes y, particularmente, a la clase pobre, por la igualdad de la justicia y por la atención con que clebe a la sociedad en general.

Un tono muy parecido puede leerse en la solicitud enviada a su majestad el emperador por parte de la comunidad de Tepoztlán. ${ }^{38}$ Refiriéndose a Maximiliano, los representantes indígenas de esta comunidad señalaban que "teniendo en cuenta vuestra magnanimidad y vuestra justicia, no ha vacilado el pueblo todo ni por un momento en confiarse enteramente al patrocinio de su soberano". Más adelante, después de exponer cómo la hacienda de Cacalco había usurpado sus terrenos, expresaban:

Desde vuestro advenimiento al trono, sonó la hora de la justicia en México y ya nosotros no tenemos inconvenientes ni lo dispendioso de un juicio. Tam: poco tememos la injusticia y antes sí descansamos en la protección que V. M. ofrece a los pueblos indígenas que han sido los más desgraciados.

Hacia el final de la representación, los indígenas recordaban al emperador la insignia de su gobierno:

creemos tenemos fe en que el soberano que hoy rige los destinos de México, siendo su emblema "equidad en la justicia", impartirá al pueblo de 'Tepoztlán la que hoy demanda. De esa justicia depende su grancleza y porvenir. exp. 1.

${ }^{38}$ AGN, Gobernación, legajos vol. 1144 (1),
Además de afirmar su regocijo por la presencia del emperador, de rememorar los tiempos coloniales y de confiar en la justicia del monarca, las comunidades colmaban de epítetos la figura imperial, lo que hace pensar que la idea que los indígenas tenían de Maximiliano y, por ende, de la autoridad, era de magnanimidad, humanidad, filantropía, bondad, respeto, veneración y generosidad para con ellos. En la ya citada representación de los vecinos del pueblo de San Cristóbal Nexquipayac, aparece muy claramente esta imagen magnánima del emperador: después de presentarle sus saludos, le manifestaban su conformidad por tener al frente del gobierno de "nuestro desventurado país a un personaje tan lleno de bondad, tan caracterizado de justo y tan publicado de humano", que practicaba además una "inexplicable compasión hacia el desgraciado". Igualmente, la comunidad de Santa María, en su ya mencionada solicitud, entregada por su cacique, Gregorio Cordero: "me postro rendidamente con sentimiento del más profundo respeto y veneración". La mirada paternal era también solicitada en la representación del pueblo de Tepoztlán ya citada. Le recordaban a Maximiliano cómo el día 25 de junio de 1864 -el documento tiene fecha de agosto 28 del mismo año- había recibido a una comisión del pueblo que, con el objeto de felicitarlo, había pasado por la corte imperial. Evocaban cómo, el encargado por el pueblo para dirigirle la palabra, lo había hecho en los siguientes términos: "Tal vez muy pronto señor, tendréis que oír una queja [del pue- 
blol y los motivos de que han emanado sus desgracias, y entonces dignaos echarle una mirada paternal." La ocasión de su solicitud, decía la comunidad, era el momento para de que se le dirigiera esa mirada paternal.

Hay que tener cuidado al interpretar este tipo de expresiones, porque se podría aducir que los indígenas escribían lo que tenían que escribir para halagar y comprometer a su gobernante; además, es seguro que en estos mismos términos se dirigieron a otros personajes prominentes de la política decimonónica mexicana. Por tanto, hay que contextualizar este tipo de expresiones. En el caso que nos ocupa, su contexto tiene que ver con la particular relación que en doble vía establecieron Maximiliano y los indígenas. De parte del emperador existía el deseo de ayudar a resolver los problemas de los indígenas. De parte de las comunidades, ya lo hemos afirmado, había una memoria histórica colectiva con una significación, respecto a la figura del rey, que la dotaba de magnanimidad, justicia, paternalismo y beneficio. Beneficios y paternalismo que también pudieron haber esperado de Juárez y de Porfirio Díaz, pero que de Maximiliano, dado el carácter de su legislación agraria y su tipo de discurso referido a ellas, tendrían más posibilidades de obtener.

En apoyo a nuestra argumentación, diremos además que, aunque este tipo de discurso sonara inicialmente como para comprometer o halagar, no era solamente así, sino que mostraba una identificación con el imperio. Tal categoría la tomamos de Barrington
Moore, que señala que, en el imperio alemán, esa identificación con el imperio surgí́ entre la clase obrera como respuesta a los posibles ataques del enemigo exterior; pero, no obstante,

hay bases para afirmar que las causas de la identificación surgían espontáneamente entre los propios trabajadores, pues todos ellos deseaban recibir un trato humano y vivir como seres humanos $[\ldots]{ }^{39}$

¿Acaso en el fondo de las representaciones enviadas a Maximiliano por los indígenas estaba presente ese deseo de recibir un trato humano y que, dado el carácter bondadoso y paternalista del imperio, lo hubieran identificado con el régimen y con el carácter de su cabeza visible, al punto de considerarlo como su posible salvación? Ya hemos señalado cómo, en las representaciones que estudiamos, las comunidades identificaron a la república como la causante de sus desgracias:

Como quiera, señor, que las desgracias de esta pobre patria nacieron cuanclo, apenas consumada la gloriosa emancipación, hubiera podido entrever [se] un porvenir venturoso, parece que como consecuencia necesaria, nacieron también en particular las desgracias de los pueblos,

se puede leer en una de ellas. ${ }^{40}$ En el orden de ideas propuesto por Moore, diremos que la atribución al origen de la república del inicio de sus pade-

${ }^{39}$ Moore, Injusticia, 1996, p. 218.

${ }^{40}$ Representación enviada por la comunidad de Tepoztlán al emperador, agosto 28 de 1864 , AGN, Gobernación, legajos vol. 1144 (1), expls. 1. 
cimientos, hizo que las comunidades, ante el colapso del liberalismo en 1863 y el establecimiento del imperio, se identificaran con éste y con Maximiliano, con la esperanza de que les dieran el trato justo que la república y los gobiernos liberales no les habían otorgado.

Su rechazo del establishment liberal y su aceptación e identificación con el segundo imperio, se pueden palpar en la impugnación que algunas de las comunidades hicieron de sus autoridades mestizas locales y en su reconocimiento del emperador como autoridad suprema. Hemos encontrado representaciones en las que, efectivamente, se solicita a Maximiliano cambiar la autoridad local por considerarla poco digna de su cargo. En la ya citada solicitud del pueblo de Santa María, el cacique Gregorio Cordero expuso que, dado que los males del pueblo tenían, en buena parte, su origen en las acciones emprendidas por el comisario municipal del pueblo y por sus aliados, Felipe Sánchez y los Laras,

ninguno de ellos merece la confianza pública ya por su mal proceder en el cumplimiento de las leyes $[\ldots]$ y como porque no queremos que éstos se mezclen en nuestros negocios porque queremos que todo sea dirigido por su majestad imperial.

Una mención más directa a la autoridad y la confianza que las comunidades atribuyeron a Maximiliano se puede leer en la solicitud que los vecinos de Santa Catalina Agotzingo enviaron al emperador en demanda de unas tierras que un tal Guadalupe Pé- rez y un fulano llamado Abrán Espinoza querían adjudicarse. Después de exponer su problema, solicitaban al emperador que suspendiera cualquier procedimiento en favor de las personas que intentaban adueñarse de los terrenos de la comunidad "con la potestad y mando imperial que su majestad tiene sobre todos nosotros pues conocemos que su majestad es la base y piedra fundamental de donde dimanan todas las leyes que gobiernan en nuestro imperio". ${ }^{41}$ En este enunciado, la imagen de Maximiliano aparece como la representación misma de la ley y de la justicia.

Una posible veta documental para seguir explorando esta identificación y aceptación de las comunidades con Maximiliano y su imperio, podrían ser las adhesiones presentadas al emperador. Recordemos que, en las negociaciones que condujeron a establecer el segundo imperio, Maximiliano exigió la adhesión del pueblo, misma que fue recogida por el general Forey y su ejército. ¿Qué dijeron las comunidades en relación con esa adhesión? ¿Fueron intimidadas por las tropas francesas para sacarles un sí a favor de la misma? ¿Su aceptación del imperio fue por voluntad propia? Por el momento sabemos que, cuando los vecinos de Trasfiguración Pozi y San Miguel Tecpan, pueblos pertenecientes a Monte Alto y sujetos al distrito de Tlalnepantla, enviaron una representación al emperador para que les fueran adjudicados en propiedad los terrenos que constituían su

${ }^{41}$ AGN, Gobernación, legajos vol. 1144 (1), exp. 2 . 


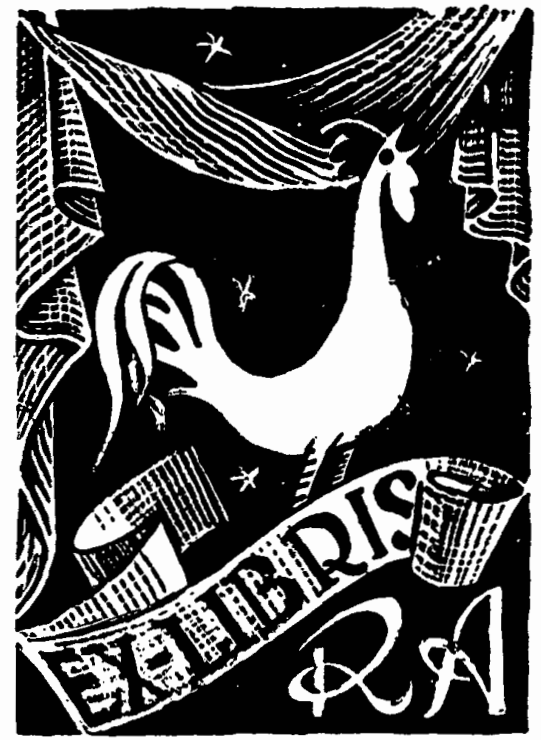

fundo legal, le hicieron saber su adhesión:

Nuestra constante y franca adhesión al orden y al Imperio, que hemos sostenido con nuestras propias armas y recursos, velando siempre por la seguridad de las propiedades rústicas y de los propietarios". 22

Otra posible vía de seguimiento de esta adhesión e identificación, es la de analizar el impacto que sobre las comunidades, tuvieron los viajes del emperador de México rural. De uno de esos viajes, citamos el testimonio de Manuel Rivera Cambas:

${ }^{42}$ AGN, Junta Protectora de las Clases Menesterosas, vol. II, exp. 26, f. 356.
[Cuando viajaba al interior], era saludaclo Maximiliano a su paso por las poblaciones, con el mismo estrćpito que se le mostró desde Córdoba a México, con gritos que parecían de alegría y reconocimiento, y se preparaba todo para que el camino estuviera $\mathrm{cu}$ bierto de flores, distinguiéndose los inclígenas en atestiguar la confianza que tenían en sus soberanos $[\ldots]{ }^{43}$

Retomando la idea de Moore sobre la identificación de los obreros alemanes con el imperio, por la demanda de un trato humano, señala este autor que dicho trato consistía en lograr la "aceptación en el orden social existente, con modificaciones en dirección de una mayor igualdad, pero para nada hacia su derrocamiento revolucionario." "É En el caso de las comunidades indígenas mexicanas era, ante todo, el reclamo de la justicia debida ancestralmente, y también el respeto a sus más acendradas tradiciones, siendo la más importante la tenencia colectiva de la tierra; estas tradiciones habían sido socavadas por los procesos de modernización iniciados por el Estado nacional, como dijimos. En las solicitudes que analizamos pudimos notar que, en casi todas ellas, las comunidades culpan a la república de las desgracias de los pueblos; de ello podemos deducir que, con la llegada de un nuevo orden de cosas -el imperio-, las comunidades esperaran, ahora sí, el trato humano que solicitaban con pruebas documentales y razones de tipo histó579.

${ }^{43}$ Citado por Pani, "Verdaderas", 1995, p.

${ }^{44}$ Moore, Injusticia, 1996, p. 219. 
rico y cultural, a la vez que con un tipo de discurso envolvente, alegórico acerca de la figura del emperador, y comprometedor, esperanzador y lleno de sentimiento y apesadumbramiento, con lo cual esperaban suscitar una mirada paternal. Como lo hemos establecido con anterioridad, Maximiliano y su Junta de Protección a los Menesterosos no fueron sordos a este llamado, y prodigaron ciertamente ese paternalismo, que se reflejaría no solamente en la ley, sino también en las acciones: por ejemplo, resolviendo prontamente las peticiones de los indigenas a su favor; ${ }^{45}$ igualmente en el tipo de discurso utilizado para dirigirse a los pobres y menesterosos.

\section{ECONOMIA Y AGRAVIO MORAL DURANTE EL SEGUNDO IMPERIO}

En 1864, valiéndose del Ayuntamiento y de una comisión especial, los vecinos de la villa de Ahualulco, departamento de San Luis, dirigieron una representación a su majestad para quejarse de los atentados que, contra 800 familias de la comunidad, estaba cometiendo el administrador de la hacienda de Bocas, cercana a la población. Para poner remedio a sus males, solicitaban que el emperador persuadiera a Francisca Pérez Gálvez, dueña de la mencionada hacienda, de

\footnotetext{
is De la rapidez con que la Junta resolvió los asuntos presentados como queja por parte de las comunidades, habla Meyer, "Junta", 1993, p. 337. También afirma que ello dio pie para estimular la antigua capacidad popular para litigar y suplicar justicia al rey.
}

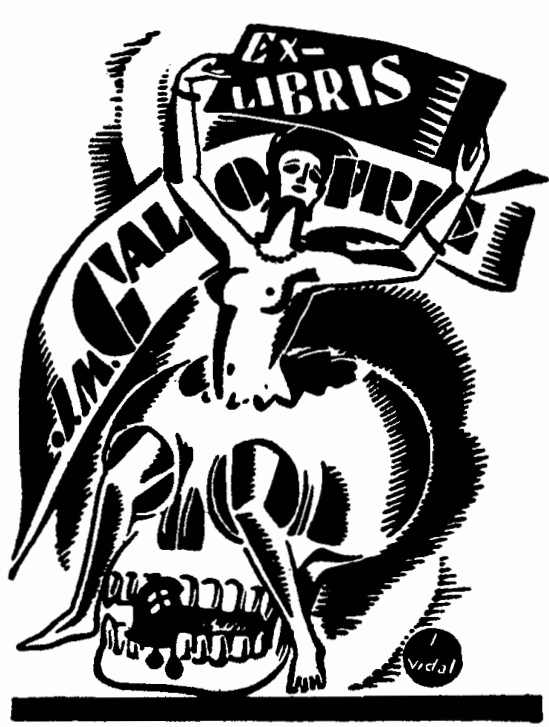

que les vendiera los terrenos en que buena parte de sus miembros vivía y laboraba. ${ }^{46}$

El primer aspecto que qucremos resaltar de esta solicitud, es que en ella se demanda la justicia y la protección del emperador para una parte

${ }^{46}$ El documento reposa en el AGN, Junta Protectora de las Clases Menesterosas, vol. J, exp. 7, ff. 143-152. La representación y parte de la documentación presentada, así como los informes salidos de reclamos, fueron publicados, a la manera de un folleto, bajo el título $R e$. presentaciones que el Ayuntamiento y vecinos de la villa de Abualulco ban elevado al señor. prefecto superior político en las cuestiones que tienen con la bacienda Estancia de Bocas y medidas que en beneficio de dicha villa ba dictado el gobierno del departamento, Tipografía del Gobierno, San Luis Potosí, 1865. 
de sus súbditos, "desvalidos y expuestos a perecer de hambre, por la consiguiente miseria en que estamos y vamos a quedar reducidos", dadas las dificultades en que los había metido el administrador de la hacienda, un tal Rafael Carlos. Como veremos más adelante, uno de sus argumentos centrales permite que nos acerquemos a la categoría "ética económica de masas" enunciada por Edward Thompson. Para este autor, en casi toda acción popular del siglo XVIII es posible detectar alguna noción legitimizante. Con este concepto de legitimación, Thompson quiere señalar que los hombres involucrados en conflictos que encerraban una situación ética respecto a su economía, la defendían con base en sus derechos o costumbres tradicionales. ${ }^{77}$ El caso que estudiamos reviste ciertas características de lo que, para el mundo rural del siglo XIX mexicano, podría ser una expresión de la ética económica de las masas, pues, en la representación que nos ocupa, podemos más o menos detectar ese carácter legitimizante que señala Thompson. A mediados del siglo xvIII, explicaba Juan Othon, comisionado de la prefectura superior de Ahualulco en la solicitud que tratamos: "se había establecido la costumbre de que los vecinos de la villa de Ahualulco abriesen labores en terrenos incultos y los hicieran productivos". La hacienda de Bocas -seguía explicando éste- cobraba "como una especie de arrendamiento a razón de seis pesos por cada , fanega de tierra y cinco pesos por

${ }^{47}$ Thompson, "Economia", 1984, p. 65. asiento de casa". De esta manera, afirmaba nuestra fuente,

los primitivos fundadores de Ahualulco, y después sus descendientes, hicieron útiles multitud de terrenos que no lo eran y, con el transcurso de los años, han formado una serie de esquilmos naturales de que no se les puede privar sin cometer una grave injusticia.

El problema radicaba en que, cuando se presentó esta representación ante las autoridades del imperio y, a través de ellas, al emperador, la hacienda de Bocas se estaba apropiando, por diferentes medios, de esos terrenos. La apelación a la costumbre, establecida desde mediados del siglo XVIII, se había elevado a la categoría de factor legitimante, lo que favorecía la solicitud de la comunidad. La defensa de estos terrenos, que la hacienda quería hacer suyos, se hacía al amparo de la costumbre, y no del derecho positivo. Es importante destacar que el comisionado de la prefectura municipal de Ahualulco hacía notar que, desde por lo menos un siglo atrás, se había establecido una costumbre que los propietarios de la hacienda estaban contraviniendo. Ahora bien, tal y como lo señala Thompson, no hay que perder de vista que el agravio cometido contra la costumbre "operaba dentro de un consenso popular en cuanto a qué prácticas eran legítimas y cuáles eran ilegítimas". En el caso que nos ocupa, el consenso de la comunidad, expresado a través de uno de sus representantes, se manifestó señalando que la hacienda, específicamente su admi- 
nistrador, estaba realizando una práctica ilegítima.

Para ser un poco más explícito acerca del manejo de este concepto, y reiterando que el caso analizado reviste ciertas características similares a las propuestas por Thompson, señalamos que, el reclamo de la comunidad de Ahualulco, se basaba en una idea tradicional de las normas y obligaciones sociales, así como de las funciones económicas -igualmente tradicionales-, desarrolladas por los actores que involucraba el conflicto. En el informe que presentó el ya citado Othon, esto de las funciones económicas queda aclarado. Se puede leer en el documento que cuando la hacienda de Bocas se hizo de los terrenos cultivados ancestralmente por los indígenas, había establecido recientemente que, en vez del arriendo que antes pagaban aquéllos, en adelante la hacienda pondría el terreno y la semilla y el mediero su trabajo, dando por resultado -de acuerdo con el relato- que, mientras el propietario no exponía nada, el mediero lo sacrificaba todo para obtener, "de cualquier manera, un resultado desfavorable y a veces notoriamente perjudicial". A renglón seguido nuestro relator elaboró la siguiente exposición:

En una fanega de sembradura de maíz se emplean estos gastos:

Para barbechar y cruzar la tierra, una yunta de bueyes, que gana de alquiler $4 \mathrm{rs}$. diarios, y un peón con $1 \frac{1}{2}$ rs. al día. 30 días empleados en esta operación, se gastan:
En sembrar se emplean doce días a cinco $1 / 2$ rs. diarios, importa este trabajo:

Para primera y segunda escarda, 24 días a $5 \frac{1}{2}$ rs.:

En dos desquelites que se practican, se gastan:

Para riegos, tomas de agua, bordos y velador:

Para pizcar, si es buena la cosecha:

10.00

Total

82.33

Después de presentarla, Othon señaló que ese presupuesto era el mínimo que podía gastarse en una fanega de sembradura, y que el máximo de producto venía a ser de 200 fanegas por una;

por manera que a la hacienda corresponden cien fanegas, habiendo arriesgado solamente una de semilla que importa, cuando mucho, tres pesos; al paso que el mediero ha puesto un capital de 82 pesos y sólo le quedan 18 pesos libres, siempre que el maíz se venda a un peso la fanega.

Concluía nuestro relator que, cuando la tierra sólo producía 60 por una, la pérdida del mediero era eviclente, "lo que sucede por lo general, a consecuencia de la escasez de lluvias y otras causas bien conocidas", las cuales no menciona. Lo interesante a destacar del documento es que pone en evidencia cómo la hacienda de Bocas atropelló los supuestos éticos que, en materia de arreglos y papeles de tipo económico, se habían establecido y manejado desde por lo menos un siglo atrás entre ésta y la comunidad, por lo cual el reclamo en demanda de justicia no se hizo esperar. 
No estamos, como es el caso de Thompson en su conocido artículo sobre la ética económica de las masas, frente a un motín de subsistencia. Es claro, sin embargo, que en el tipo de representaciones que algunas comunidades indígenas enviaron al emperador Maximiliano, estuvo presente, como argumento a sus reclamos, una legitimidad que les había otorgado la corona española a través del Derecho indiano. Dicha legitimidad así como tal Derecho, desde la independencia y su correspondiente introducción de los principios liberales, había sido vulnerada y atacada. El sentido de estas solicitudes y peticiones era el de defender la tradición y la costumbre con respecto al derecho a la tierra. No diremos, como lo comprueba Thompson en el caso de los motines por hambre en la Inglaterra del siglo XvII, que en el caso que nos ocupa hubo el deseo explícito por parte de la autoridad de aprobar y reconocer la legitimidad del reclamo, pero sí, que había en el emperador y en la Junta Protectora de las Clases Menesterosas la voluntad de entender y de dar una solución positiva al problema del despojo y deslinde de tierras planteado por los indígenas.

Muy cercano al concepto de ética económica de las masas que hace Thompson, está el planteamiento de Moore sobre el agravio ético en las bases sociales de obediencia y rebelión. En el contexto del siglo XIX mexicano, las hipótesis planteadas por estos dos autores pueden aplicarse y son complementarias, aunque con distintos matices. En relación con el periodo que estudiamos, es claro que el agravio ético está implícito. Si bien es cierto que, en algunos aspectos, el espíritu de las leyes de desamortización de bienes comunales era el de favorecer la propiedad individual, también lo es que los abusos contra la propiedad de las comunidades indígenas se incrementaron, estando incluso a la orden del día. Desde la perspectiva de las comunidades, independientemente de que con este tipo de leyes se pretendiera modernizar la estructura del campo mexicano, se estaba imponiendo un tipo de relaciones sociales que violaban las que, en el pasado colonial, habían sido consideradas como "decentes". Para Moore, la violación de las reglas sociales son componentes fundamentales del agravio ético del sentimiento de injusticia. También afirma que sin reglas que gobiernan la conducta social, no podrían existir sentimientos de agravio ético o el de injusticia social. En su sentido más esencial, dice, es coraje por la injusticia lo que uno siente cuando otra persona viola una regla social. ${ }^{48}$ Frente a un nuevo tipo de legislación agraria que, en ocasiones, se prestó al abuso, las comunidades indígenas percibieron un sentimiento de injusticia y agravio moral. Antes hemos mencionado cómo uno de los fundamentos del reclamo de las comunidades es la falta de justicia para con ellas. Con Moore diremos que ese reclamo de justicia se fundamentaba en el agravio moral. Del ya citado informe de Juan Othon sobre la representación que envió la comunidad al emperador, se deducen el

\footnotetext{
${ }^{48}$ Moore, "Injusticia", 1996, p. 18.
} 
agravio moral y ético de la injusticia social planteada por Moore. Una de las "iniquidades" que se cometen al despedir a un arrendatario -afirmó Othon-, "es obligarlo a que dé el millar de maguey a 40 pesos, cuando el ciento vale, cuando menos, esa suma". Además de esa iniquidad que debemos entender en términos de injusticia, habló de que se había "llevado la crueldad hasta quitarle a una infeliz mujer un telar que le servía para el sostén de su familia" y de que a un octogenario "se le haya dejado en el campo, sin tener donde guarecerse de la intemperie". También habló de que los vecinos de Ahualulco "sufren violenta opresión por parte de la hacienda de Bocas"; advirtió que si se quería que "aquellas familias vivan tranquilas en sus hogares, y no se lancen a la carrera del crimen, estrechadas por la miseria, debe a mi juicio tendérseles por el supremo gobierno una mano protectora". ${ }^{49}$

¿Por qué se rebelan las personas? Es una pregunta amplia. En términos generales, Moore nos dirá que la injusticia y el abrupto cambio de las reglas con que, tradicionalmente, una sociedad ha funcionado, constituyen la base de la desobediencia y de la rebeldía. En función de nuestro trabajo, diremos que el proyecto liberal del siglo XIX, y no sólo en México sino en todos los países donde fue establecido, sentó, en aras de la modernidad y para algunos grupos, sociales, las bases de la injusticia social. Y cuan-

${ }^{49}$ AGN, Junta Protectora de las Clases Menesterosas, vol. I, exp. 7, f. 152 y pp. 16 y 17 de la representación en su versión publicada. do hablamos de ciertos grupos nos estamos refiriendo a aquellas comunidades inmersas por siglos en reglas del juego sustentadas en la tradición, en acuerdos verbalizados, no escritos; en la costumbre y no en el derecho positivo.

\section{CONCLUSIONES}

Ilasta hace poco tiempo, en la conciencia histórica del mexicano, y aun dentro del gremio de los historiadores, al llamado segundo imperio se lo tenía muy escondido, ya que ocuparse de él atentaba contra el honor patrio. Sin embargo, el ser nacional monárquico mexicano, como lo ha afirmado O'Gorman, existió en el transcurrir de la historia mexicana y como tal hay que aceptarlo.

Llama la atención que, en ese segundo imperio, algunas comunidades indígenas se hayan sentido identificadas con el régimen político establecido por Maximiliano. Como lo hemos planteado, ellas percibicron la llegada del monarca como la de un ser superior que vendría a remediar su crítica situación. Esta percepción y representación mental que el indígena mexicano se hizo de Maximiliano, iba aunada con la de un personaje lleno de magnanimidad, justicia, solidaridad y benevolencia; es en esta percepción que las comunidades tuvieron, tanto del imperio como de Maximiliano, que se puede identificar un "imaginario monárquico" heredado de los tiempos coloniales, mismo que resistió los embates de la modernidad y que reapareció en los ticmpos 
del segundo imperio. Nuestra hipótesis tendría que ser complementada con un estudio psicohistórico que profundizara en las "virtudes" y los sentimientos que el archiduque abrigó como emperador de los mexicanos, y particularmente en los desplegados hacia los indígenas pues, en relación con dichas comunidades, no todo en Maximiliano fue romántico. Sin embargo, los trabajos de la Junta, la legislación agraria, sus viajes para conocer la situación de sus súbditos, sus audiencias y la amabilidad mostrada con el común, son pruebas del indigenismo profesado por el archiduque.

Sería muy interesante poder seguir explorando nuestras hipótesis, a la luz del primer imperio mexicano, y aún más, poder revisar los últimos momentos del periodo virreinal, para establecer con certeza si, según la ideación de las comunidades indígenas, las nociones de monarquía e imperio aparecían como una alternativa real frente al liberalismo. También sería importante analizar la dinámica que, a través de sus representaciones, establecieron las comunidades con los liberales para saber qué tan patriarcales, benevolentes y justicieros los consideraban. Ello lo planteamos pensando en que el tono con que las comunidades se dirigieron a Maximiliano, mucho pudo haber tenido de eufemismo, es decir, que este tipo de discurso altamente suplicante fuera simplemente la forma para conseguir un fin determinado. ¿Era simplemente la táctica empleada por las comunidades, tanto con los liberales como con Maximiliano? Por el momento hemos planteado que las comunidades se basaron en su pasado colonial inmediato, donde se les había protegido de los excesos del régimen político y que, partiendo de allí, emprendicron esta lucha para recuperar la tierra. También apelaron al derecho consuetudinario y a sus tradiciones $y$, cuando nada funcionó y el agravio ético rebasó los límites de la decencia, se rebelaron: siguieron pidiendo justicia, pero también se armaron.

\section{ARCHIVOS}

ANG, Archivo General de la Nación, fondos Gobernación y Junta Protectora de las Clases Menesterosas.

\section{HEMEROGRAFÍA}

El Pájaro Verde, México.

\section{BiBLIOGRAFÍ}

-Advenimiento de SS. MM. II. Maximiliano y Carlota al trono de México. Documentos relativos y narración del viaje de nuestros soberanos de Miramar a Veracruz y del recibimiento que se les bizo en este último puerto y en las ciudades de Córdoba, Orizaba, Puebla y México, Imprenta de J. M. Andrade y F. Escalante, México, 1864.

-Arenal, Jaime del, "La protección del indígena en el segundo imperio mexicano: La Junta Protectora de las Clases Menesterosas", Arts Iuris, núm. 6, 1991.

-Arrangoiz, Francisco de Paula de, Apuntes para la bistoria del segundo imperio mexicano, Imprenta de M. Rivadeneyra, México, 1869.

-Blassio, José Luis, Maximiliano íntimo. El emperador Maximiliano y su 
corte. Memorias de un secretario particular, Bouret, París/México, 1905.

-Borah, Woodrow, El Juzgado General de Indios en la Nueva España, Fondo de Cultura Económica, México, 1985.

-Colección de leyes, decretos y reglamentos que interinamente forman el sisterna politico, administrativo y judicial del imperio, Imprenta de A. Boix, México, 1865 , vol. v.

-Croix, Carlos Francisco de, Instrucción del virrey marqués de Croix que deja a su sucesor Antonio María Bucareli, Jus, México, 1960.

-González y González, Luis, "El indigenismo de Maximiliano" en Arturo Arnaiz y Freg y Claude Bataillon, La intervención francesa y el imperio de Maximiliano. Cien años después, 1862-1962, Asociación Mexicana de Historiadores/Instituto Francés de América Latina, México, 1965.

- Guerra, Fraçois Xavier, México. Del antiguo régimen a la revolución, Fondo de Cultura Económica, México, 1985, t. I.

-Hidalgo, José María, Proyectos de monarquía en México, F. Vázquez editor, México, 1904.

-Landavazo Arias, Marco Antonio, "EExacción o lealtad?: Los indios ante la coyuntura de las guerras borbónicas en Nueva España", Cuicuilco. Revista de la Escuela Nacional de Antropología e Historia, vol. 2, núm. 7, 1996.

$$
\text { , "Vuestra incansable ge- }
$$

nerosidad'. Reacciones novohispanas ante la invasión napoleónica", en prensa.

-Marichal, Carlos, "Las guerras imperiales y los préstamos novohispanos, 17811804", Historia Mexicana, vol. XxxIX, núm. 4, 1990.

-Meyer, Jean, "La Junta Protectora de las Clases Menesterosas. Indigenismo y agrarismo en el segundo imperio" en Antonio Escobar, Indio, nación y comunidad en el México del siglo XIX, CIESAS/ Centro de Estudios Mexicanos y Centroamericanos, México, 1993.

- De Miramar a México. Viaje del emperador Maximiliano y de la emperatriz Carlota, desde su palacio de Miramar cerca de Trieste, hasta la capital del imperio mexicano, con una relación de los festejos públicos con que fueron obse. quiados en Veracruz, Córdoba, Orizaba, Puebla, México, y en las demás poblaciones del tránsito, Imprenta de J. Bernardo Aburto, Orizaba, 1864.

-Moore, Barrington, La injusticia: bases sociales de la obediencia y la rebelión, Universiclad Nacional Autónoma de México, México, 1996.

-O'Gorman, Edmundo, La supervivencia politica novo-bispana. Reflexiones sobre el monarquismo mexicano, Condumex, México, 1969.

-Pani, Erika, " $i$ Verdaderas figuras de Cooper o pobres inditos infelices? La política indigenista de Maximiliano", Historia Mexicana, vol. XLVII , núm. 187, 1995.

-Quirarte, Martín, Historiografía sobre el imperio de Maximiliano, Universidad Nacional Autónoma de México, México, 1993.

-Thompson, Edward, "La economía moral de la multitud en la Inglaterra del siglo XVII" en Tradición, revuelta y conciencia de clase. Estudios sobre la crisis de la sociedad preindustrial, Editorial Crítica, Barcelona, 1984.

-Zamacois, Niceto, Historia general de México, J. F. Parrés \& Compañía Editores, México, 1880 , t. XVI. 


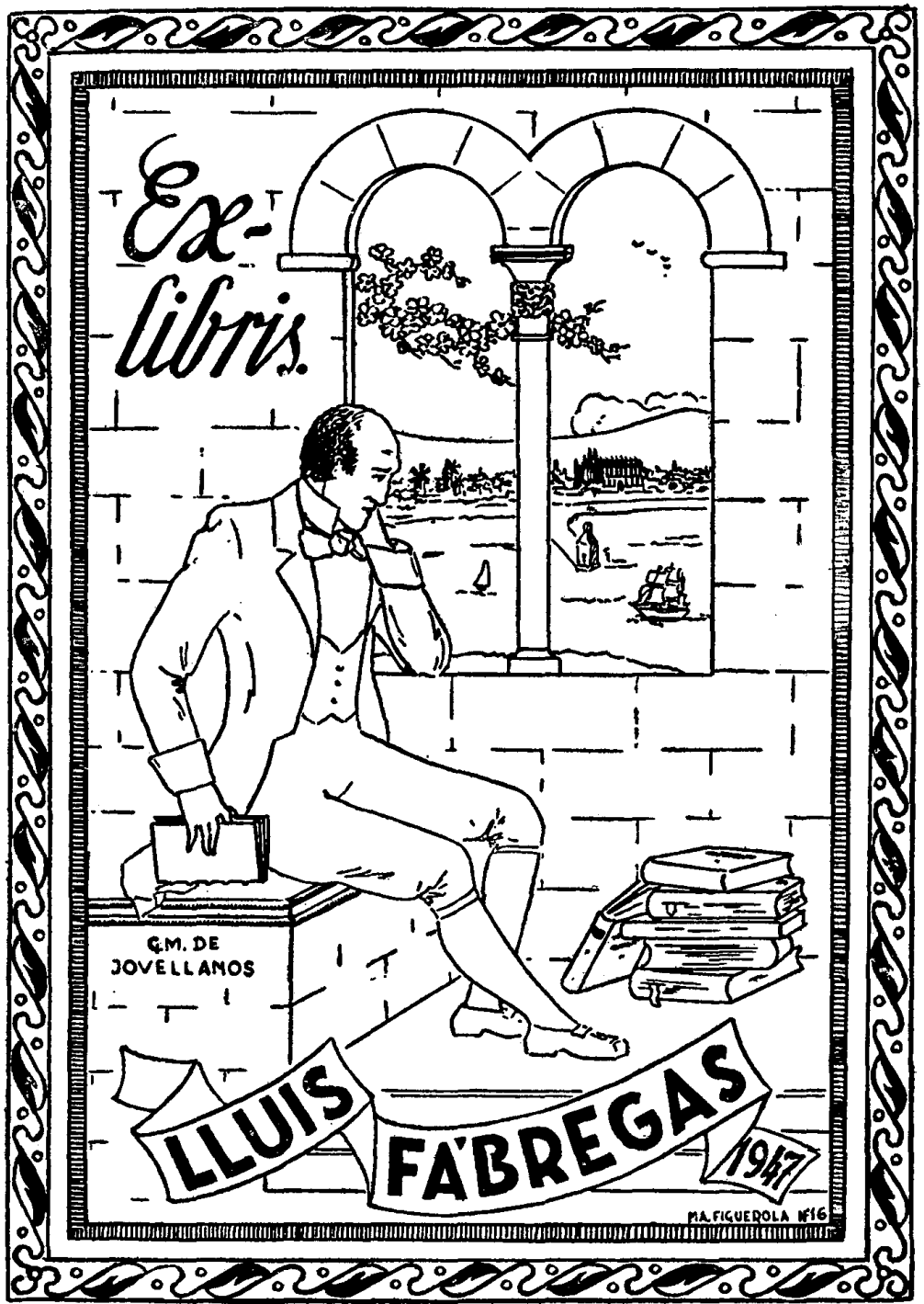

